\title{
Tibolone among drugs in the therapy of postmenopausal women
}

\section{Corresponding author:}

Adrianna Nieciecka, Collegium Medicum, Nicolaus Copernicus University, e-mail: a.nieciecka@wp.pl
Medical Research Journal 2021; Volume 6, Number 2, 140-146 DOI: 10.5603/MRJ.a2021.0014 Copyright (C) 2021 Via Medica ISSN 2451-2591 e-ISSN 2451-4101

\begin{abstract}
The ageing of society is undoubtedly a success, but also a challenge of modern medicine. Postmenopausal women struggle with many health problems, and their treatment recommended so far is often associated with many side effects such as the increased risk of hormone-dependent tumours or thromboembolism. The purpose of this article is to discuss the effects of a relatively new drug called tibolone against the currently recommended treatment. The unique mechanism of estrogenic, progestogenic, and androgenic action of tibolone is due to the breakdown of the parent compound into 3 active metabolites, each selectively acting on different tissues differently. Tibolone is approved for the relief of menopausal symptoms and its effectiveness is similar to that of hormone replacement therapy and the prevention of osteoporosis. The article will also discuss the results of various studies on the risk of cancer during treatment with tibolone, especially in comparison to hormone replacement therapy. Tibolone affects also the cardiovascular system, including reducing the level of lipoprotein a, total cholesterol, triglycerides, and HDL. Tibolone also has a neuroprotective effect and improves mood and libido. Like all medicines, tibolone is not free from side effects such as weight gain, vaginal bleeding, hirsutism, and inflammation of the reproductive organs, so the benefits and risks of therapy should always be considered. There are still no clear conclusions regarding many aspects of the influence of tibolone on the patient's body, therefore large studies are needed to assess the effectiveness and safety of tibolone.

Key words: tibolone, menopause, hormone replacement therapy, neoplasms, osteoporosis
\end{abstract}

Med Res J 2021; 6 (2): 140-146

\section{Introduction}

The ageing of societies is a global phenomenon. In 2015, the population of people over 60 years old accounted for $12 \%$ of the world's population, and the number is increasing every year. It is estimated that by 2050 the elderly people will constitute as much as $21.5 \%$ of the population. These changes are particularly visible in Europe. The data published by the European Commission in 2011 shows that by 2060 , approximately $30 \%$ of Europe's population will be over 65 years old [1]. While this is undeniably a sign of medical progress, it brings new challenges. In the elderly population, multi-morbidity is characteristic [2]. The typical problems among elderly people include diseases of the musculoskeletal system, the cardiovascular system, the nervous system, metabolic diseases, weakening of the body's defence systems, hormonal changes, and mental and social problems [1]. Preservation of the physical activeness and the quality of life of the elderly, enabling their independent functioning requires the cooperation of specialists in various medical and paramedical fields. This involves taking multiple medications, that are not free from side effects [2]. That is why dynamically developing medicine faces the challenge of improving these therapies. One of the solutions is to look for new, alternative drugs. In this article is presented the application of Tibolone, and its place among other drugs used to treat the postmenopausal women population. About its indications and unique properties, but also the dangers and limitations of the use of this drug.

\section{The unique mechanism of action of tibolone}

Tibolone was synthesized in 1964 by Organon Research and Development Laboratories in the Neth- 
erlands, but it took 25 years of research to be finally approved for use [3]. It has been widely used in many countries for many years but has not been introduced in the USA yet [4]. It differs from other drugs by selective action on different tissues in a different way. This synthetic steroid has been classified as a selective regulator of estrogenic activity in tissues (STEAR) [3]. The reason why tibolone is so unique is that the parent compound, structurally similar to norethynodrel and virtually no pharmacological activity, is converted in the body into 3 active metabolites: $3 \alpha$-hydroxytibolone, $3 \beta$-hydroxytibolone, and the $\Delta 4$ isomer. Each of these compounds has a different effect. $3 \alpha$-hydroxytibolone and $3 \beta$-hydroxytibolone are weak oestrogens and bind to oestrogen receptors in the vagina, brain, and bone with minimal effect on the endometrium. In addition, hydroxymetabolites inhibit the action of sulfatase, which leads to a decrease in the conversion of oestrogen to oestradiol in the breast so that the estrogenic stimulation is lower. Whereas the $\Delta 4$-isomer shows progestogenic activity mainly on the endometrium, which reduces its proliferation. $\Delta 4$-isomer also has an androgenic effect in the brain and the liver, affecting lipid levels. Regarding the effects on the breasts, the $\Delta 4$ isomer inhibits the proliferation of breast tissue and stimulates its apoptosis [4].

Tibolone has been approved for the treatment of climacteric symptoms and the prevention of osteoporosis occurring in women who are at least one year after menopause [5]. It has a positive effect on the mental and sexual spheres. Studies also show that tibolone prevents endometrial proliferation and vaginal atrophy, and also relieves urogenital symptoms.

The overall tolerance of tibolone is also assessed as good [6].

\section{Menopausal symptoms}

Every ageing woman experiences physiological hormonal changes in her body. Over the years, ovarian follicles are lost, and the levels of hormones secreted by them decrease. This leads to an increase in $\mathrm{FSH}$ levels, which is a major feature of the menopausal transition [7]. Each woman starts menopause individually, usually between the ages of 45 and 52 [8]. In addition to menstrual disorders, this period is associated with the emergence of significant and bothersome clinical symptoms, which increase with the duration of the menopausal transition. First and foremost, they include hot flashes, as well as poor sleep, urogenital atrophy, and unfavourable mood [7].

Most women experience vasomotor symptoms, i.e., hot flushes and night sweats. They are most pronounced a few years before and immediately after their final menstrual period, but a small percentage of women will never be free from them. In addition to reducing the quality of life, hot flushes can negatively affect health because this symptom has been shown to correlate with reduced heart rate variability, which is associated with a higher risk of cardiovascular disease. About a quarter to a third of menopausal women experience vaginal symptoms that, unlike hot flashes and sleep disturbances, do not go away without treatment [7]. They include several troublesome ailments such as itching of the vulva, vaginal dryness, vaginal discharge, dyspareunia, or dysuria [9].

Studies are suggesting the effectiveness of complementary and alternative medicine in reducing stress and the nuisance of symptoms related to menopause, such as cognitive behavioural therapy and phytoestrogens [8]. Patients may also be offered paroxetine mesylate or clonidine for vasomotor symptoms or a low dose of gabapentin at night when hot flushes occur at night, ospemifene (a new selective oestrogen receptor modulator - SERM) for vaginal dryness, and selective serotonin reuptake inhibitors (SSRI) or melatonin receptor agonists for other symptoms. However, most often women with the typical symptoms of menopause are offered hormone therapy [7]. They are effective in combating vasomotor symptoms (they reduce the frequency of symptoms by $75 \%$ and their intensity by $87 \%$ ) and urogenital atrophy, prevent bone loss, reduce the risk of type 2 diabetes and ischemic heart disease, and improve mood and quality of life. Hormone therapy can be divided into oestrogen-only therapy (when the woman has had a hysterectomy) and oestrogen-progesterone therapy (adding a dose of progesterone is necessary because oestrogen alone would stimulate endometrial cell division) [10]. Vaginal oestrogen therapy is the method of choice in the treatment of urogenital atrophy, thanks to which complications related to systemic therapy are not observed [9]. It is important to remember about the side effects of hormone replacement therapy, such as mastodynia, fluid retention, nausea, leg cramps, headache, uterine bleeding, increased risk of thromboembolism (it seems that the solution could be the percutaneous supply of oestrogen, which poses a lower risk of a thromboembolic event) as well as depression, anxiety, bloating and increased appetite if the progesterone component is also included. And in long-term follow-up, they can lead to the development of tumours, which will be discussed in more detail later in this article [10-12].

Alternative therapy is the administration of tibolone, which, due to its unique mechanism of action, also works well in alleviating menopausal symptoms, and studies comparing oral hormone replacement therapy with tibolone shows similar effectiveness. At the same time, the incidence of vaginal bleeding and breast ten- 
derness is lower than with standard HRT [11, 12]. In a study comparing transdermal oestrogen (although it was performed in a small group of patients), statistically better results of transdermal oestrogen than tibolone were reported. However, in another study comparing the effects of tibolone and transdermal oestrogen in surgically menopausal women, tibolone was more effective [12].

In conclusion, tibolone should be preferred in women who experienced undesirable side effects after hormone replacement therapy and who have already gone through menopause and are struggling with acute menopausal symptoms [10].

\section{Tibolone and cancer risk}

Hormone replacement therapy is undoubtedly a risk factor for cancer of oestrogen-dependent tissues. Women taking combined oestrogen-progesterone therapy have an increased risk of developing breast cancer, while oestrogen-only therapy does not appear to increase that risk. On the other hand, the risk of endometrial cancer is increased with oestrogen-only therapy and the addition of progesterone reduces it [13]. The risk of developing ovarian cancer is increased in both oestrogen and oestrogen-progesterone therapy [14]. Since many women and their doctors are concerned about HRT, another treatment like tibolone could be considered.

The tissue-selective $\Delta 4$-metabolite of tibolone with progestogenic properties prevents the proliferation of endometrial cells, therefore additional progesterone is not required during this therapy. Endometrial atrophy has been observed in several years of clinical observations of the use of tibolone. The safety of tibolone therapy was compared to that of continuous oestrogen-progesterone therapy with a lower percentage of irregular bleeding and spotting from the genital tract. In a small study conducted by the Medical University of Warsaw, none of the women, during the 12-month follow-up, revealed cancer or endometrial adenoplasma. Atrophic changes of the endometrium were found and were associated with a low percentage of vaginal bleeding. However, there have been some reports in the literature of endometrial adenocarcinomas in women treated with tibolone [15].

According to a Danish study, postmenopausal tibolone substitution is associated with an overall increased risk of ovarian and endometrial cancer. This is especially true of serous ovarian tumours and type I endometrial cancer. The risk increases with the longer duration of therapy [14]. An epidemiological study was also carried out in the UK and it was found that women treated with tibolone for at least 2 years had a higher risk of developing endometrial cancer compared to women using hormone replacement therapy, although the authors of this study emphasize that tibolone was not always prescribed under the license for use in women who are at least one year postmenopausal or have been prescribed for women with a previous history of uterine bleeding. Therefore, more detailed research on the relationship between the use of tibolone and the occurrence of endometrial neoplasms is necessary [16].

A complication of hormone replacement therapy (especially when oestrogen alone) may also be the reactivation of endometriosis and stimulation of malignant transformation in women with a history of endometriosis. Due to the lack of high-quality studies, it is not possible to clearly indicate the best treatment option for these women. The authors of some studies indicate that tibolone may be a safer alternative, but there is no clear evidence for it [17].

It is worth remembering that breast cancer is the most common malignant neoplasm of women in developed countries and one of the leading causes of death in women over 60 years old [18]. As already mentioned, studies have shown that in the breast, tibolone metabolites regulate the activity of enzymes that are locally involved in the production of oestrogens (the activity of which explains why the risk of breast cancer does not decrease after menopause) and have antiproliferative and proapoptotic effects on cells. Animal studies in rats, monkeys and nude mice have shown efficacy in inhibiting the growth of breast tumours (at the level of tamoxifen efficacy) and preventing tumour growth. There are also studies that in women with a history of breast cancer treated with tamoxifen, tibolone was effective and safe in relieving menopausal symptoms. Contrary to standard HRT, breast tenderness was less frequent in women treated with tibolone [19].

However, the Million Women Study conducted in the UK found a significant increase in the number of breast cancer cases in women using tibolone. Although it was much lower than with oestrogen-progesterone therapy (leading to an approximately fourfold increase in the risk of breast cancer), it was still slightly higher than with oestrogen-only therapy [20].

Another side effect of HRT is an increase in the density of mammograms, making it difficult to interpret this important breast cancer screening test. Tibolone does not show this effect. Some studies even report a decrease in mammography density after the use of tibolone. Although epidemiological studies show an increased risk of breast cancer in women treated with tibolone, it may be related to the increased detection of cancer in radiological tests [19].

Moreover, some clinical studies suggest that tibolone may reduce the risk of colon cancer [3]. 
All of this suggests that tibolone may have an advantage over standard HRT in terms of breast cancer risk, but this is not certain enough to make it lose oncological alertness.

\section{The effect of tibolone on the cardiovascular system}

Oestrogen deficiency in postmenopausal women is also associated with many changes in the vascular system. With age, the blood pressure value and lipid profile change, vascular reactivity decreases, glucose tolerance is impaired, and thus the cardiovascular risk increases. The effectiveness of HRT in reducing cardiovascular events is so far debatable [21]. A serious complication of HRT is a significantly increased risk of thromboembolism [10]. Also, clinical and observational studies have confirmed that standard HRT doses increase the relative risk of stroke, especially in women over 60 years of age [22].

The tibolone discussed in this article has been shown to reduce Lp (a), total cholesterol, and triglycerides in clinical trials as well as HDL cholesterol levels. High levels of LDL-C, Lp (a) and triglycerides, and low levels of HDL-C are associated with an increased risk of cardiovascular disease [23]. While it is emphasized that $L p(a)$ is an independent risk factor for cardiovascular disease and lowering $L p(a)$ levels may be critical in preventing CVD, and changes in HDL-C levels are transient, there are no long-term studies to support the theory that a decrease in Lp (a) does indeed lead to a reduction in cardiovascular events [24]. Moreover, no significant difference was found between the effect of tibolone and standard HRT on Lp (a) concentration [25].

The fall in oestrogen levels may make hypertension more common in menopausal women. Due to the occurrence of hypertension in young women taking contraceptive pills and inconclusive results of studies on the effect of HRT on blood pressure, the influence of tibolone in this aspect was discussed. In a randomized trial in hypertensive women, no clinically significant changes in blood pressure were found between the tibolone and placebo-treated groups. The authors considered tibolone $2.5 \mathrm{mg}$ safe for use in women treated or untreated [26]. However, in the study comparing the effect of Drospirenone combined with $17 \beta$-oestradiol (E2) with tibolone, it was concluded that tibolone does not show vascular function resulting from estrogenic properties, most likely due to additional progesterone and androgenic component [21].

Interesting results of the OPAL study also report the progression of atherosclerosis, as measured by the progression of carotid intima-media thickness, in both tibolone and standard HRT therapy compared to placebo, which may be associated with an increased cardiovascular risk. However, other, smaller studies do not confirm this relationship [27].

Other factors that appear to increase the risk of cardiovascular disease are increased levels of fibrinogen and low levels of antithrombin III. Despite previous reports on the profibrinolytic activity of tibolone, the meta-analysis of studies does not suggest either a significant reduction in fibrinogen concentration or changes in plasma ATIII concentration, regardless of the duration of treatment with tibolone. The authors of this meta-analysis suggest that this form of therapy is neutral in terms of the occurrence of thromboembolic events $[4,27]$.

Concerns about the safety of tibolone arose during the Fracture Incidence Study in the Elderly Osteoporosis Population (LIFT), which was discontinued due to an observed increased risk of stroke [3, 27]. However, results from the General Practice Research Database indicate that tibolone was not associated with an increased risk of stroke [22]. The differences may be because women in the LIFT study had a more severe medical history [3].

In conclusion, there is still a lack of conclusive and reliable scientific data to determine the overall effect of tibolone on cardiovascular morbidity and mortality [26].

\section{Osteoporosis}

Four main groups of drugs are used during osteoporosis: bisphosphonates, selective oestrogen modulating receptor, parathyroid hormone derivatives and strontium ranelate. The limitations of pharmacotherapy with bisphosphonates include gastrointestinal complaints, atrial fibrillation or significant impairment of functions, i.e., diseases occurring among geriatric patients. Raloxifene - a selective oestrogen receptor modulator - may increase vasomotor symptoms and increase symptoms of thromboembolism. Parathyroid hormone derivatives have serious ineffectiveness among people with kidney failure or hypercalcemia. The use of strontium ranelate in concomitant dysfunction of the kidney will prove to be inappropriate. The numerous options of the above-mentioned drugs encourage the search for alternative therapies, which include tibolone [28].

In postmenopausal women, the risk of osteoporosis increases significantly due to the decreased synthesis of oestrogens, especially 17-b-estradiol [29]. The role of these hormones is to inhibit osteoblast apoptosis and reduce the viability of osteoclasts due to the interaction with cytokines that regulate the death processes of these cells [30]. In addition, oestrogens reduce calciuria, which also helps to maintain the body's calcium-phosphate balance [29]. Scientific studies have 
shown that tibolone, due to the content of oestrogens, reduces the risk of vertebral and extra-vertebral osteoporotic fractures [31]. An additional advantage is the presence of androgens that stimulate the synthesis of new bone tissue, which in turn causes a greater increase in bone density compared to oestrogen-only therapy. The anti-resorptive effect of tibolone is dose-dependent $-2.5 \mathrm{mg}$ of the drug inhibits resorption more effectively than the use of $1.25 \mathrm{mg}$ [30]. It is suggested that the lower dose should be used in asymptomatic patients or as part of maintenance therapy, and the higher dose in the presence of severe symptoms of menopause [32]. Tibolone turns out to be particularly beneficial in women after an osteoporotic fracture or with the presence of risk factors for such a fracture, in the case of contraindications to the use of denosumab and bisphosphonates, as well as in patients with particularly severe vasomotor symptoms of menopause [33, 34]. Due to the proven cartilage-protective properties of some selective oestrogen receptor modulators, one study raised the question of whether such an effect would also be observed in the case of tibolone. However, no such relationship has been demonstrated, which may be related to the effect on receptors other than oestrogen receptors [35].

\section{Central nervous system}

Sex hormones also regulate many processes within the central nervous system. There are two types of oestrogen receptors in the brain. Within the hypothalamus, the majority are alpha receptors, while beta receptors dominate within the structures responsible for motor and cognitive functions [30]. In animal studies, the stimulating effect of oestrogens on the synaptogenesis process in the hypothalamus and increasing the number of spines of dendritic pyramidal cells in the hippocampus has been proven. It is assumed that the disappearance of dendritic spines is caused by the activity of the GABA-ergic system, which increases with oestrogen deficiency. Particularly noteworthy is the fact that androgens act antagonistically to GABA receptors [36]. Progesterone also stimulates the process of synaptogenesis and myelination [37]. Therefore, tibolone has a positive effect on the learning process and memory, and in particular, improves semantic memory [38]. However, there are reports of an adverse effect of tibolone on the performance of activities requiring concentration and task planning [39].

It has also been shown that oestrogens influence the processes regulating oedema, astrogliosis and the inflammatory response following brain damage [40]. Their protective effect against astroglia and microglia cells under inflammatory conditions was also observed.
It is worth emphasizing that progesterone also protects nerve cells against the influence of factors inducing oxidative stress [42]. Interestingly, tibolone regulates the phagocytosis of astrocytes more effectively in women than in men [42].

When discussing the various implications of tibolone pharmacotherapy, one should not forget about the increase in the level of neurotransmitters in the cholinergic and serotonergic systems. In addition, the drug regulates the phosphorylation of the Tau protein, which plays a key role in the pathogenesis of tauopathies such as, for example, Alzheimer's disease. Its neuroprotective effect should be considered in the context of its use in the treatment of postmenopausal neurodegenerative diseases [38].

\section{Mood and cognitive functions}

Neuroendocrine and metabolic changes taking place during menopause adversely affect the mental sphere of patients - symptoms of depression or anxiety often appear [39]. Lowered mood and libido may also result indirectly from vasomotor symptoms [43]. After the tibolone therapy, an improvement in mood was observed, and beneficial effects were also noted in women struggling with the problem of chronic fatigue or reduced motivation [30].

The positive influence on the mental aspects can be explained by several mechanisms. Firstly, scientific studies have shown that oestrogens affect serotonergic, dopaminergic and adrenergic neurotransmission and increase the concentration of beta-endorphins in both plasma and pituitary gland $[30,39]$. It is presumed that the increase in the level of androgens positively correlates with the level of beta-endorphins [39]. These chemical compounds are endogenous opioids influencing thermoregulation, behavioural functions and showing analgesic properties [44]. It was also proved that tibolone increased their concentration and stimulated the synthesis of allopregnanolone - a neurosteroid that acts agonistically in relation to the GABAa receptor [39, 44]. Stimulating the activity of this receptor reduces the level of anxiety and has a sedative effect [39].

\section{Sexual functions}

In the menopausal period, a frequently reported complaint is a decrease in the level of satisfaction with sex life [43]. Oestrogen deficiency predisposes to the development of atrophic vaginosis and urethral syndrome. These diseases are one of the causes of dyspareunia, which negatively affects the quality of sexual life [30]. In addition, decreased libido may be 
a result of a decrease in androgen levels, as well as a consequence of accompanying mood disorders. Oestrogens positively influence the function of nerves in the genital system and increase vaginal lubrication [43]. It has been shown that tibolone reduces the symptoms of atrophic inflammation, stimulates vaginal blood flow and stimulates lubrication $[30,45]$. Thanks to its affinity to androgen receptors and the reduction of SHBG concentration in the plasma, it increases the concentration of free testosterone, which is responsible for maintaining normal libido. As a consequence, patients more often undertake sexual contacts and report an increase in desire, excitement and satisfaction with intercourse [39].

\section{Other side effects}

Side effects in patients taking tibolone not covered in the above considerations include abdominal pain, weight gain and bloating. Some patients reported vaginal bleeding, breast tenderness, genital pruritus, headaches, the hirsutism. [5] Short-term increases in serum transaminases were also noted in clinical trials. Several cases of liver injury correlating with treatment have been reported. Treatment has been identified as causing clinical liver injury, but the mechanism is unknown. So far, there have been no cases of acute liver failure, death, or chronic hepatitis [46].

Two studies suggest that tibolone may worsen the vaginal infection, although neither of them has provided an aetiology. One study reports urinary tract infections [47]. There was a case of a patient with polycythaemia secondary to the use of tibolone [48]. In in vitro studies, tibolone induces the proliferation of glioblastoma cells, which may be related to its activity at oestrogen and progesterone receptors. However, it does not affect the migration or invasiveness of neoplastic cells [49].

\section{Conclusions}

According to data published by the European Commission, every third adult will be over 65 by the end of 2060 . The progressive ageing of society is not only an economic challenge but also a medical one, which is why it is so important to focus the scientific development on ailments that often occur among geriatric patients. This idea led us to discuss drug therapy with tibolone. Its uniqueness and the possibility of utilizing pleiotropic effects is because, despite being classified as a selective regulator of estrogenic activity, it also has progestogenic and androgenic effects. Tibolone may be used as an alternative therapy in patients who do not tolerate conventional hormone replacement therapy because it shows similar effectiveness and greater effectiveness in reducing breast tenderness or vaginal bleeding. The effect on cancer development is uncertain - studies describing an increased risk of endometrial cancer and a decreased likelihood of developing breast cancer compared to HRT are emerging. The effect of tibolone on the cardiovascular system remains inconclusive - some studies suggest that it accelerates the progression of atherosclerosis and is pro-fibrinolytic, but other articles present just the opposite conclusions. Tibolone reduces the risk of vertebral and non-vertebral fractures, especially in women with a previous fracture or with risk factors. Concerning the central nervous system, a neuroprotective effect, improvement in semantic memory and learning, as well as an unfavourable effect in the field of task planning, have been noted. In the described studies, tibolone turned out to be effective in patients with increased anxiety or decreased motivation, which most likely results from the increased concentration of beta-endorphin in the body. Due to the increase in vaginal flow and lubrication, women reported an increase in sexual satisfaction. The most common side effects include weight gain, headaches and abdominal pain, vaginal itching and bleeding, and hirsutism. Summarizing this article, the mechanisms of action and clinical implications of tibolone are still not fully understood. It is necessary to conduct further research on this drug, which may significantly affect the effectiveness of pharmacotherapy in the population of geriatric patients.

\section{Conflict of interests: The authors declare that they have no competing financial interests.}

\section{References}

1. Zalega T. Proces starzenia sie społeczeństwa-wybrane aspekty. Zarzadzanie Innowacyjne w Gospodarce i Biznesie. 2018; 1(26): 121-139.

2. Zdziebło K. Współczesne zjawiska demograficzne a problemy zdrowotne starzejącego się społeczeństwa. Studia medyczne. 2008; 9: 63-69.

3. Kloosterboer HJ. Historical milestones in the development of tibolone (Livial $®$ ). Climacteric. 2011; 14(6): 609-621, doi: 10.3109/13697137.2011.580639, indexed in Pubmed: 21942642.

4. Swegle JM, Kelly MW. Tibolone: a unique version of hormone replacement therapy. Ann Pharmacother. 2004; 38(5): 874-881, doi: 10.1345/aph.1D462, indexed in Pubmed: 15026563.

5. Dębski R, Kotarski J, Paszkowski T, et al. Stanowisko Zespołu Ekspertów Polskiego Towarzystwa Ginekologicznego na temat zastosowania tibolonu w ramach menopauzalnej terapii hormonalnej. Menopause Review/Przegląd Menopauzalny. 2009; 8(1): 1-5.

6. Kenemans P, Speroff L. International Tibolone Consensus Group. TiboIone: clinical recommendations and practical guidelines. A report of the International Tibolone Consensus Group. Maturitas. 2005; 51(1): 21-28, doi: 10.1016/j.maturitas.2005.02.011, indexed in Pubmed: 15883105.

7. Santoro N. Perimenopause: From Research to Practice. J Womens Health (Larchmt). 2016; 25(4): 332-339, doi: 10.1089/jwh.2015.5556, indexed in Pubmed: 26653408.

8. Johnson A, Roberts L, Elkins G. Complementary and Alternative Medicine for Menopause. J Evid Based Integr Med. 2019; 24: 2515690X19829380, doi: 10.1177/2515690X19829380, indexed in Pubmed: 30868921.

9. Baranowski W, Debski R, Paszkowski T, et al. Rekomendacje Polskiego Towarzystwa Menopauzy i Andropauzy dotyczące stosowania lokalnej terapii hormonalnej u kobiet w okresie menopauzy. Przegląd Menopauzalny. 2011; 15(4): 263 
10. Fait T. Menopause hormone therapy: latest developments and clinical practice. Drugs Context. 2019; 8: 212551, doi: 10.7573/dic.212551, indexed in Pubmed: 30636965

11. Umland EM, Falconieri L. Treatment options for vasomotor symptoms in menopause: focus on desvenlafaxine. Int J Womens Health. 2012; 305-319, doi: 10.2147/IJWH.S24614, indexed in Pubmed: 22870045

12. Kim HK, Jeon SH, Ryu KiJ, et al. Comparison of the Efficacy of Tibolone and Transdermal Estrogen in Treating Menopausal Symptoms in Postmenopausal Women. J Menopausal Med. 2019; 25(3): 123-129 doi: 10.6118/jmm.19205, indexed in Pubmed: 32307937.

13. Ito K. Hormone replacement therapy and cancers: the biological roles of estrogen and progestin in tumorigenesis are different between the endometrium and breast. Tohoku J Exp Med. 2007; 212(1): 1-12, doi 10.1620/tjem.212.1, indexed in Pubmed: 17464097.

14. Løkkegaard EC, Mørch LS. Tibolone and risk of gynecological hormone sensitive cancer. Int J Cancer. 2018; 142(12): 2435-2440, doi 10.1002/ijc.31267, indexed in Pubmed: 29349823.

15. Szlendak-Sauer K, Wierzba W, Radowicki S. Wpływ stosowania tiboIonu na obraz endometrium u kobiet po menopauzie. Ginekologia Polska, 2008; 79. ; 11: 758-761.

16. de Vries CS, Bromley SE, Thomas $\mathrm{H}$, et al. Tibolone and endometrial cancer: a cohort and nested case-control study in the UK. Drug Saf. 2005; 28(3): 241-249, doi: 10.2165/00002018-200528030-00005 indexed in Pubmed: 15733028.

17. Gemmell LC, Webster KE, Kirtley S, et al. The management of menopause in women with a history of endometriosis: a systematic review. Hum Reprod Update. 2017; 23(4): 481-500, doi: 10.1093/humupd/dmx011, indexed in Pubmed: 28498913.

18. Husejko J, Porada M, Bieniek D, et al. Breast cancer as a significant social problem. J Educ Health Sport. 2019; 9(8): 412-423.

19. Wang $\mathrm{PH}, \mathrm{Cheng} \mathrm{MH}, \mathrm{Chao} \mathrm{HT}$, et al. Effects of tibolone on the breas of postmenopausal women. Taiwan J Obstet Gynecol. 2007; 46(2): 121-126, doi: 10.1016/S1028-4559(07)60005-9, indexed in Pubmed: 17638619

20. Green J, Reeves GK, Floud S, et al. Million Women Study Collaborators, Million Women Study Collaborators, Million Women Study Collaborators, Million Women Study Collaborators, Million Women Study Collaborators, Million Women Study Collaborators, Million Women Study Collaborators, Million Women Study Collaborators, Million Women Study Collaborators, Million Women Study Collaborators. Breast cance and hormone-replacement therapy in the Million Women Study. Lancet. 2003; 362(9382): 419-427, doi: 10.1016/s0140-6736(03)14065-2 indexed in Pubmed: 12927427.

21. Vitale C, Mammi C, Gambacciani M, et al. Effect of hormone replacement therapy with the anti-mineralocorticoid progestin Drospirenone compared to tibolone on endothelial function and central haemodynamics in post-menopausal women. Int J Cardiol. 2017: 227: 217-221, doi: 10.1016/j.ijcard.2016.11.149, indexed in Pubmed: 27843051.

22. Henderson WW, Lobo RA. Hormone therapy and the risk of stroke perspectives 10 years after the Women's Health Initiative trials. Climacteric. 2012; 15(3): 229-234, doi: 10.3109/13697137.2012.656254, indexed in Pubmed: 22612608.

23. Anagnostis P Bitzer $\mathrm{J}$, Cano A et al Menopause symptom management in women with dyslipidemias: An EMAS clinical guide. Maturitas. 2020; 135: 82-88, doi: 10.1016/j.maturitas.2020.03.007, indexed in Pubmed: 32209279

24. Kotani K, Sahebkar A, Serban C, et al. Lipid and Blood Pressure Meta-analysis Collaboration (LBPMC) Group. Tibolone decreases Lipoprotein(a) levels in postmenopausal women: A systematic review and meta-analysis of 12 studies with 1009 patients. Atherosclerosis. 2015; 242(1): 87-96, doi: 10.1016/j.atherosclerosis.2015.06.056, indexed in Pubmed: 26186655.

25. Anagnostis $\mathrm{P}$, Galanis $\mathrm{P}$, Chatzistergiou $\mathrm{V}$, et al. The effect of hormone replacement therapy and tibolone on lipoprotein (a) concentrations in postmenopausal women: A systematic review and meta-analysis. Maturitas. 2017; 99: 27-36, doi: 10.1016/j.maturitas.2017.02.009, indexed in Pubmed: 28364865

26. Lloyd G, McGing E, Cooper A, et al. A randomised placebo controlled trial of the effects of tibolone on blood pressure and lipids in hypertensive women. J Hum Hypertens. 2000; 14(2): 99-104, doi: 10.1038/sj.jhh.1000938, indexed in Pubmed: 10723115

27. Bała M, Sahebkar A, Ursoniu S, et al. Lipid Blood Pressure Meta-Analysis Collaboration Group. Effects of tibolone on fibrinogen and antithrombin III: A systematic review and meta-analysis of controlled trials. Pharmacol Res. 2017; 124: 64-73, doi: 10.1016/ phrs.2017.07.024, indexed in Pubmed: 28760491.

28. Skalska A. Efekt działania tybolonu u kobiet w starszym wieku w okresie pomenopauzalnym. Gerontologia Polska, 2008, tom 16, nr. ; 3: 183.

29. Smektała A, Dobosz A. Osteoporoza - patofizjologia, objawy, profilaktyka i leczenie. Farmacja Polska. 2020; 6: 344.
30. Notelovitz M. Postmenopausal tibolone therapy: biologic principles and applied clinical practice. MedGenMed. 2007; 9(1): 2, indexed in Pubmed: 17435612

31. Gambacciani M, Cagnacci A, Lello S, et al. Italian Menopause Society (SIM), International Menopause Society, International Menopause Society Writing Group, International Menopause Society Expert Workshop, Executive Committee of the International Menopause Society. The osteoporosis dilemma. Gynecol Endocrinol. 2004; 18(2): 59-61, doi: 10.1080/09513590310001651812, indexed in Pubmed: 15195495.

32. Gambacciani M, Ciaponi M, Cappagli B, et al. A longitudinal evaluation of the effect of two doses of tibolone on bone density and metabolism in early postmenopausal women. Gynecol Endocrinol. 2004; 18(1): 9-16, doi: 10.1080/09513590310001651722, indexed in Pubmed: 15106359.

33. Cummings SR, Ettinger B Delmas PD et al. LIFT Trial Investigators. The effects of tibolone in older postmenopausal women. $\mathrm{N}$ Engl J Med. 2008; 359(7): 697-708, doi: 10.1056/NEJMoa0800743, indexed in Pubmed: 18703472

34. Eastell R, Rosen CJ, Black DM, et al. Pharmacological Management of Osteoporosis in Postmenopausal Women: An Endocrine Society* Clinical Practice Guideline. J Clin Endocrinol Metab. 2019; 104(5): 15951622, doi: 10.1210/jc.2019-00221, indexed in Pubmed: 30907953

35. Karsdal MA, Byrjalsen I, Leeming DJ, et al. Tibolone inhibits bone resorption without secondary positive effects on cartilage degradation. BMC Musculoskelet Disord. 2008; 9: 153, doi: 10.1186/1471-2474-9153, indexed in Pubmed: 19019210.

36. Laçin S, Oruç S, Karaca S, et al. Assessment of the effectiveness of postmenopausal tibolone therapy on neural functions by measuring visual evoked potentials: a placebo-controlled study. Eur J Obstet Gynecol Reprod Biol. 2001; 98(1): 72-76, doi: 10.1016/s03012115(01)00295-0, indexed in Pubmed: 11516803.

37. Henderson VW. Progesterone and human cognition. Climacteric. 2018; 21 (4): 333-340, doi: 10.1080/13697137.2018.1476484, indexed in Pubmed: 29852783

38. Pinto-Almazán R, Segura-Uribe JJ, Farfán-García ED, et al. Effects of Tibolone on the Central Nervous System: Clinical and Experimental Approaches. Biomed Res Int. 2017; 2017: 8630764, doi: 10.1155/2017/8630764, indexed in Pubmed: 28191467.

39. Genazzani AR, Pluchino N, Bernardi F, et al. Beneficial effect of tibolone on mood, cognition, well-being, and sexuality in menopausal women. Neuropsychiatr Dis Treat. 2006; 2(3): 299-307, doi: 10.2147/nedt.2006.2.3.299, indexed in Pubmed: 19412477

40. Martin-Jiménez C, Gaitán-Vaca DM, Areiza N, et al. Astrocytes Mediate Protective Actions of Estrogenic Compounds after Traumatic Brain Injury. Neuroendocrinology. 2019; 108(2): 142-160, doi: 10.1159/000495078, indexed in Pubmed: 30391959.

41. Hidalgo-Lanussa O, Baez-Jurado E, Echeverria V, et al. Lipotoxicity, neuroinflammation, glial cells and oestrogenic compounds. J Neuroendocrinol. 2020; 32(1): e12776, doi: 10.1111/jne.12776, indexed in Pubmed: 31334878 .

42. Crespo-Castrillo A Garcia-Segura LM, Arevalo MA The synthetic steroid tibolone exerts sex-specific regulation of astrocyte phagocytosis under basal conditions and after an inflammatory challenge. J Neuroinflammation. 2020; 17(1): 37, doi: 10.1186/s12974-020-17196 , indexed in Pubmed: 31992325

43. Davis SR. The effects of tibolone on mood and libido. Menopause. 2002; 9(3): 162-170, doi: 10.1097/00042192-200205000-00004, indexed in Pubmed: 11973439.

44. Genazzani AR, Bernardi F, Pluchino N, et al. Effect of tibolone administration on central and peripheral levels of allopregnanolone and beta-endorphin in female rats. Menopause. 2006; 13(1): 57-64, doi: 10.1097/01.gme.0000191372.79052.d3, indexed in Pubmed: 16607099.

45. Gupta B, Mittal P, Khuteta R, et al. A Comparative Study of CEE, Tibolone, and DHEA as Hormone Replacement Therapy for Surgical Menopause. J Obstet Gynaecol India. 2013; 63(3): 194-198, doi: 10.1007/s13224-012-0297-7, indexed in Pubmed: 24431637.

46. LiverTox: Clinical and Research Information on Drug-Induced Liver Injury [Internet]. Bethesda (MD): National Institute of Diabetes and Digestive and Kidney Diseases; 2012-. Tibolone. [Updated 2020 Sep 2]. https://www.ncbi.nlm.nih.gov/books/NBK548180/.

47. Formoso G, Perrone E, Maltoni S, et al. Short and long term effects of tibolone in postmenopausal women. Cochrane Database Syst Rev. 2012(2): CD008536, doi: 10.1002/14651858.CD008536.pub2, indexed in Pubmed: 22336846.

48. Staples L, Milder T, Choi PYI. Polycythaemia Secondary to Hormone Replacement Therapy with Tibolone. Case Rep Hematol. 2017; 2017: 3476349, doi: 10.1155/2017/3476349, indexed in Pubmed: 29090100.

49. González-Arenas A, De la Fuente-Granada M, Camacho-Arroyo I, et al. Tibolone Effects on Human Glioblastoma Cell Lines. Arch Med Res. 2019; 50(4): 187-196, doi: 10.1016/j.arcmed.2019.08.001, indexed in Pubmed: 31499479. 